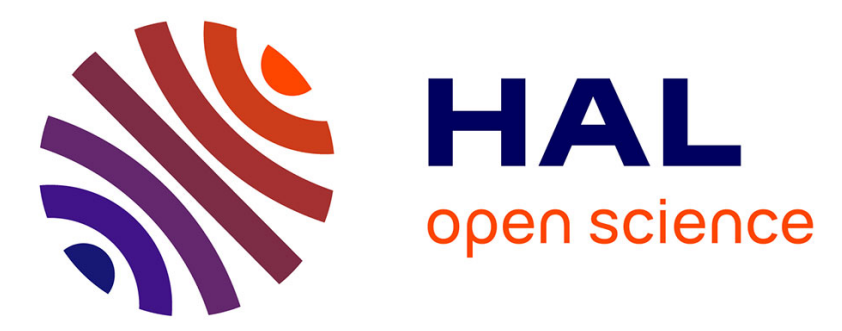

\title{
Research on Method of Image Extraction for Crop Monitoring with Multi Rotor UAV
}

\author{
Wei Ma, Xiu Wang, Lijun Qi, Cuiling Li
}

\section{To cite this version:}

Wei Ma, Xiu Wang, Lijun Qi, Cuiling Li. Research on Method of Image Extraction for Crop Monitoring with Multi Rotor UAV. 10th International Conference on Computer and Computing Technologies in Agriculture (CCTA), Oct 2016, Dongying, China. pp.489-495, 10.1007/978-3-030-06155-5_50 . hal-02179967

\section{HAL Id: hal-02179967 https://hal.inria.fr/hal-02179967}

Submitted on 12 Jul 2019

HAL is a multi-disciplinary open access archive for the deposit and dissemination of scientific research documents, whether they are published or not. The documents may come from teaching and research institutions in France or abroad, or from public or private research centers.
L'archive ouverte pluridisciplinaire HAL, est destinée au dépôt et à la diffusion de documents scientifiques de niveau recherche, publiés ou non, émanant des établissements d'enseignement et de recherche français ou étrangers, des laboratoires publics ou privés. 


\title{
Research on method of image extraction for crop monitoring with multi rotor $\mathrm{UAV}$
}

\author{
Wei Ma ${ }^{1}$, Xiu Wang ${ }^{1}$, Lijun $\mathrm{Qi}^{2(\bowtie)}$, and Cuiling $\mathrm{Li}^{1}$ \\ ${ }^{1}$ Beijing National Research Center of Intelligent Equipment for Agriculture/Beijing Key \\ Laboratory of Intelligent Equipment Technology for Agriculture, Beijing Research Center \\ of Intelligent Equipment for Agriculture, Beijing 100097 China (Tel: 86-010-51503346;e- \\ mail: maw516@163.com;Xiuwang@263.net); \\ ${ }^{2}$ College of Engineering, China Agricultural University, Beijing 100083 \\ China(e-mail: qilijun@cau. edu. cn)\}
}

\begin{abstract}
In this paper, the distribution of weeds in winter wheat was obtained by UAV. A model is established by $\mathrm{K}$ value clustering and edge detection algorithms. Key images of different flying angle of UAV for farmland weeds were extracted. The research results show that the edge detection algorithm is suitable for UAV image processing. The recognition accuracy of the weeds was more than $90 \%$. The accuracy of the identification of three typical grass conditions is achieved $98.3 \%$. The conclusion of the study is to provide guidance for UAV variable spraying.
\end{abstract}

Keywords: K value clustering, edge detection, UAV monitoring

\section{$1 \quad$ Introduction}

The traditional agricultural monitoring mainly focuses on the research and application of satellite remote sensing platform,It is found that the old methods can not meet the urgent need for the timely and accurate diagnosis and management of the crop under these conditions of the climate change, the complex conditions of the geographical environment. Satellite remote sensing technology can not be effectively used for the monitoring of agricultural pests and diseases. There are a number of reasons:Satellite remote sensing is easy to be affected by rainy weather, high price, time and space resolution, low spectral resolution. In order to solve this problem, the scholars believe that research and development of new UAV(unmanned aerial vehicle) monitoring system, air detection technology and the development of new plant protection technology based on model aerial platform become a very important research direction of the current agricultural condition monitoring and protection without manmachine control system technology.

The UAV platform has the advantages of flexible and flexible operation, high selectivity, high accuracy, short operation period, good timeliness, low maintenance cost, economic and practical, and good security. Small multi rotor unmanned aircraft with modern information means to achieve information on the analysis of crop information, and integrate geographic information system (GIS), the global positioning system (GPS), image processing technology and sensor technology to guide precision spraying system automation application. These technologies will bring unprecedented development opportunities for information acquisition and crop pest plant protection technology with micro UAV. Automatic spraying theory was studied in Japan by the Yamaha Corporation with the help of GPS navigation and positioning to achieve application not overlap, and save a lot of pesticide. Agricultural plant protection aircraft have more than 2000 in Japan, and more than $50 \%$ of the pesticide were completed by UAV. American scholars study application method with UAV based on agricultural condition monitoring method. The monitoring method was applied in more than 4000 aircraft of agricultural plant protection UAV. operations spraying of $65 \%$ chemical pesticides was completed by UAV. The research of this field in China starts late. on the of crop disease, insect pest and weed aviation acquisition and 
analysis based on UAV were carried out. The spraying droplet air drift control based on UAV was in-depth studied. But image extraction method for agricultural monitoring has not been reported, the online image extraction is relation to the important link of the low altitude UAV monitoring. Research in this area has lagged behind.

\section{$2 \quad$ Materials and methods}

\section{$2.1 \quad$ Test Material}

Test object is winter wheat mixed with weeds in the field. Test field was divided into different test plots. The experiment site is located in China Agricultural University Shangzhuang experimental station in Haidian District, Beijing. The first test was in April 10, 2016. The second test was 15 days later. Multi rotor UAV is selected as a test of the aircraft platform. Fig. 1(model is M600 produced by Shenzhen Da Jiang company). The aircraft maximum load $6 \mathrm{~kg}$. Power system integrated dust and active heat dissipation function.

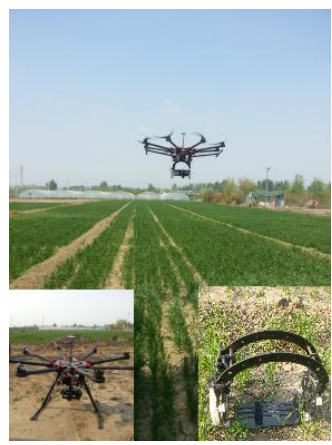

Fig. 1. UAV test platform

\section{$2.2 \quad$ Test Method}

Test area is 20 meters width, 100 meters long. Test areas were divided into four control area which is 5 meters width. There are 10 sampling areas labeled randomly as 1 square meters in each plot. Each sampling area is $1 \mathrm{~m}$ long and square. Aircraft flew from one end of the first pilot area to reach the other end after. Aircraft taking a turn around return from the second cells. Then aircraft flew over the third pilot area to the end and return from fourth cells. The test was repeated 3 times. Table 1 is in hover condition, different hovering height and different camera to obtain the corresponding parameters of the same area image. The flight parameters are mainly used to obtain the image which is used to distinguish the farmland weeds and crop growth, and to establish the information base for the specific weeds and crops.

Table 1. Hovering flight parameters

\begin{tabular}{ccccc}
\hline $\begin{array}{c}\text { Instrument } \\
\text { model }\end{array}$ & $\begin{array}{c}\text { Flight altitude } \\
/ \mathrm{m}\end{array}$ & $\begin{array}{c}\text { Resolution } \\
/ \mathrm{cm}\end{array}$ & $\begin{array}{c}\text { Flight speed } \\
\mathrm{m} / \mathrm{s}\end{array}$ & $\begin{array}{c}\text { Line spacing } \\
/ \mathrm{m}\end{array}$ \\
\hline GH 4 & 3 & 0.01 & 0.3 & 2 \\
\hline
\end{tabular}

\section{Results and Analysis}

A total of of 80 images were collected in four plots. 60 images are used to establish and train the recognition model, and the 20 images are used to tested. There are three typical grass conditions:A small amount of weeds and wheat grow together(a),a large number of weeds and wheat seriously mixed(b), and the weeds grow only between rows of wheat(c) in figure 1. Image scaling function is used to extract the typical image. As shown in Figure 1. In order to separate the crops and weeds from the farmland, first, the $\mathrm{K}$ value clustering algorithm is selected. There are 3 cluster 
centroid points selected randomly. Gray histogram of the image is obtained by the algorithm. As shown in Figure 2. So the three initial cluster centers are selected, and the distance between each pixel gray level and the cluster center is calculated. Test results are not very ideal, the land of the cracks are retained. Figures 3 and 4 are the results of the processing. The smallest cluster centers and the largest cluster centers are in search of the algorithm. All low gray level is obtained and taken as the average as the next low gray Center. The next intermediate gray center and the next high gray center are also calculated according to the same algorithm. Despite repeated optimization calculations, this problem can still not be solved. As a comparative study, a new edge detection algorithm is introduced. In order to confirm each other, there are four kinds of edge detection methods were compared:prewitt, sobel,roberts,canny. The calculation results show that the first algorithm is the best for the details.
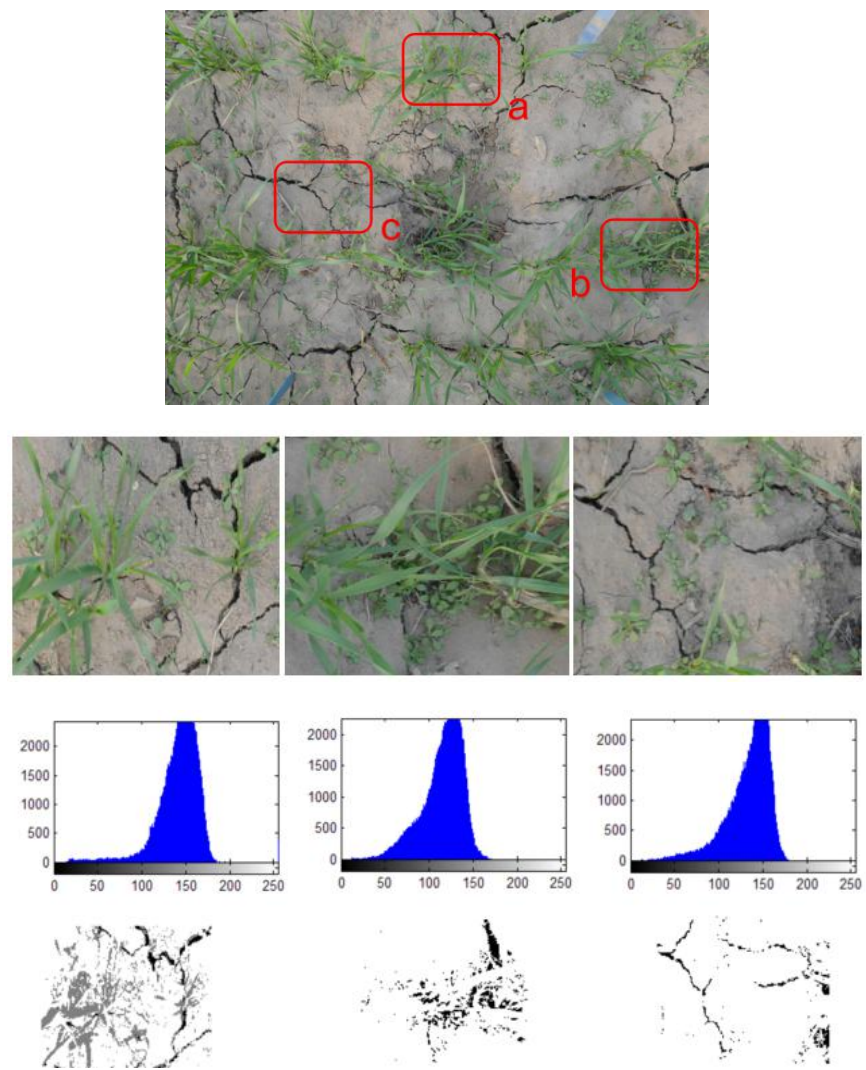

Fig. 2 Results of K clustering algorithm.

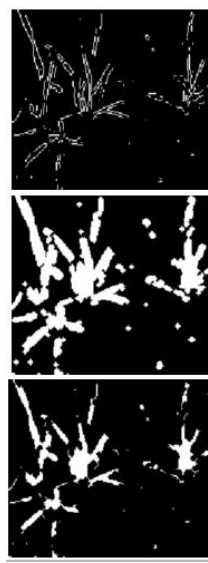

(a)

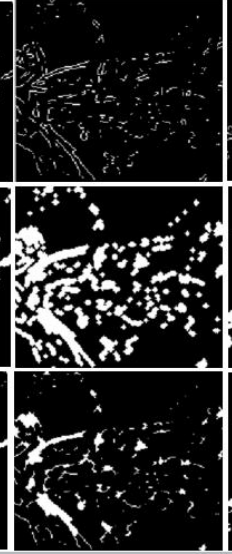

(b)

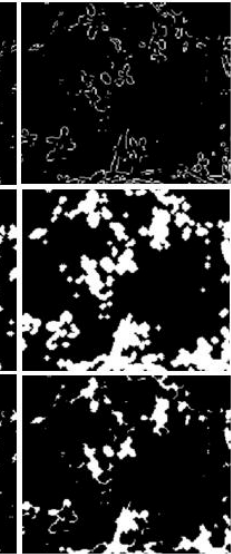

(c)

Fig. 3. The results of the classification algorithm for edge detection 


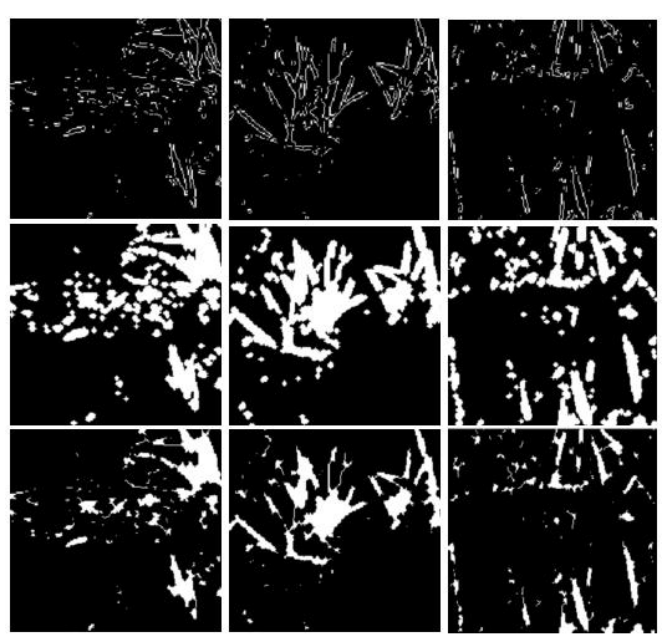

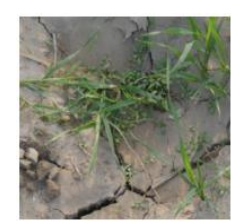

(a)

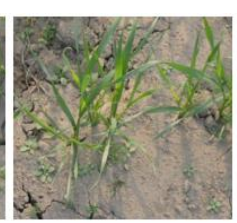

(b)

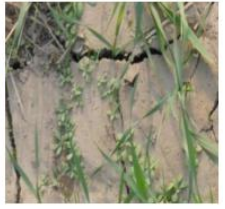

(c)

Fig. 4. Validation results for the identification model

The recognition model is established through the sample training, and the verification is carried out automatically. The soil background is well removed. Based on the results of edge detection, the vegetation area of crops and weeds is accurately acquired through the expansion of the image method. UAV flight angle on the impact of the image is also very good to remove. The research found that the UAV is easy to be disturbed by air current. Flying height and angle changes will lead to changes in the collected images. Figure 5 is the image of different types of weed growth under different field of view. It can be seen from the chart of the B column that the accuracy of the model has been decreased. The reason is that the weeds and wheat are seriously mixed and the shape of the grass is blocked. Through the improvement of the coefficient of the model, the recognition effect is better.
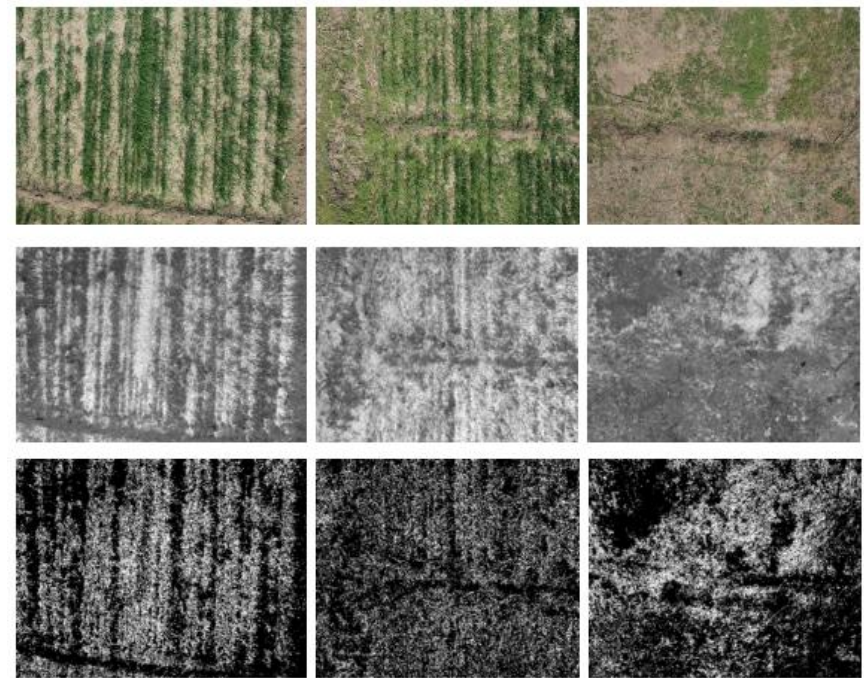

Fig. 5. The image of different types of weed growth under different field of view 
Table 2. Level of recognition accuracy

\begin{tabular}{cccc}
\hline Model & $\begin{array}{c}\text { Modeling } \\
\text { set accuracy } \\
(\%)\end{array}$ & $\begin{array}{c}\text { Test set } \\
\text { accuracy } \\
(\%)\end{array}$ & $\begin{array}{c}\text { Weed identification } \\
\text { rate } \\
(\%)\end{array}$ \\
\hline 1 & $48.5(29 / 60)$ & $45(9 / 20)$ & 51 \\
2 & $98.3(59 / 60)$ & $90(18 / 20)$ & 91 \\
\hline
\end{tabular}

The recognition accuracy of the two models is shown in Table 2. The recognition effect of the second models is better than that of the first model. The reason is that the volatility of the UAV flight is not completely eliminated by the camera.

\section{Conclutions}

In this paper, the distribution of weeds in winter wheat was obtained by UAV. A model is established by two kinds of algorithms. Key images of farmland weeds were extracted.

The research results show that the edge detection algorithm is suitable for UAV image processing. The recognition accuracy of the weeds was more than $90 \%$. The accuracy of the identification of three typical grass conditions is achieved $98.3 \%$.

\section{Ackknowledgements}

This work was supported by the National Key Research and Devement of China during the $13^{\text {th }}$ Five-Year Plan Period(No. 2017YFD0701101) and our research center Innovation team project(JNKST201619). Sincere thanks to Dr. Zhang Ruirui for helping me complete field image collection using UAV.

\section{References}

1. De Oliveira D C, Wehrmeister M A. Using Deep Learning and Low-Cost RGB and Thermal Cameras to Detect Pedestrians in Aerial Images Captured by Multirotor UAV[J]. Sensors, 2018, $18(7)$.

2. Gao Z, Deng J, Sun J, et al. Scheme and key technologies of wireless image transmission system for micro unmanned air vehicles[J]. Transactions of Beijing Institute of Technology, 2008(12): 1078-1082.

3. Gong $A$, He $X$, Lei $T$, et al. Fast image processing method of UAV without control data[J]. Geo-information Science, 2010, $12(2): 254-260$.

4. Hu K, Zhang J. Research of fixed-wing UAVs remote sensing systems for image acquisition in mountainous areas[J]. Beijing Surveying and Mapping. 2011(3): 35-37.

5. Hunt E R, Hively $W D$, Fujikawa $S$ J, et al. Acquisition of NIR-green-blue digital photographs from unmanned aircraft for crop monitoring[J]. Remote Sensing, 2010, 2(1): 290-305.

6. Huang $K$, Wang $G$, Wang $Y$. Multi-source image fusion system based on DSP[J]. Ordnance Industry Automation, $2012(2)$ : 6163.

7. Lu H, Li Y, He J, et al. Capture and processing of low altitude remote sensing images by UAV[J]. Engineering of Surveying and Mapping,2011(1): 51-54.

8. Rango A, Laliberte A, Herrick J E, et al. Unmanned aerial vehicle-based remote sensing for rangeland assessment, monitoring, and management[J]. Journal of Applied Remote Sensing, 2009, $3(1): 33542$.

9. Xiang $\mathrm{H}$, Tian L. Development of a low-cost agricultural remote sensing system based on an autonomous unmanned aerial vehicle (UAV)[J]. Biosystems Engineering, 2011(108): 174-190.

10.Xin Z, Fang $Y$, Zhang X. Adaptive control for the on-board 
pan-tilt camera in an UAV ground-target-tracking system[J]. Control Theory \&Applications, 2010(8): 1001-1006.

11.Yin Jie, Yang Kui. On the fast processing technique for low-altitude UAV RS system[J]. Bulletin of Surveying and Mapping, 2011(12): 15-17.

12. Zhou Z, Zang $Y$, Luo $X$, et al. Technology innovation development strategy on agricultural aviation industry for plant protection in China[J]. Transactions of the Chinese Society of Agricultural Engineering (Transactions of the CSAE), 2013, 29(24): 1-10. 